\title{
ANÁLISIS SOCIO-POLÍTICO DE LA CONSTRUCCIÓN DEL PAISAJE DESDE LA ETNICIDAD LIMONENSE EN COSTA RICA ${ }^{1}$
}

\author{
SOCIAL AND POLITICAL ANALYSIS OF LANDSCAPE CONSTRUCTION \\ FROM “LIMONENSE” ETHNICITY IN COSTA RICA
}

\section{Pablo Carballo Cháves*}

RESUMEN

\begin{abstract}
Desde una reflexión teórica de los paisajes, se realiza un abordaje étnico-cultural de la provincia de Limón, específicamente a través de la metodología del relato de vida. Con este abordaje se profundiza en la experiencia de tres relatores explorando las modificaciones y la reconstrucción cultural sucedida en relación con el marco general del caribeño costarricense. Se realiza un rescate analítico de los recuerdos y significados por etapas de vida —niñez, juventud $y$ adultez/vejez-, ahondando en las ideas y pensamientos de las personas entrevistadas. Se evidencia durante la etapa de la niñez una idea de colorido en ese espacio recordado; en la juventud se compara el mundo laboral y las nuevas relaciones en las dinámicas de vida más allá de los confines de la provincia; finalmente, en la adultez/ vejez se interpretan las perspectivas desde los cambios que han ocurrido en sus miradas del paisaje. Como parte de la conclusiones se muestra los matices conflictivos y diferenciales, en términos político-sociales, presentes en lo étnico-cultural.
\end{abstract}

PALABRAS CLAVE: COSTA RICA $*$ PAISAJE $*$ CULTURA * MEMORIA $*$ HISTORIA

\section{ABSTRACT}

From a theoretical reflection of landscapes, ethnic and cultural approach to the province of Limon is done, particularly using the methodology of life story and where delves into three rapporteurs on amendments and cultural reconstruction has happened in relation to the general framework of the Costa Rican Caribbean. An analytical rescue of memories and meanings is by life-childhood, youth and adulthood/old age spaces, where we consider ideas and thoughts of the people and their stories and contributed to the narrative reconstruction of the caribbbean landscapes. In childhood is evident a hankering on

$1 \quad$ Este artículo es producto del proyecto de investigación "Centros Históricos del Turismo" inscrito en la Vicerrectoría de Investigación con el nro. 211-B0-246. Este documento es la continuación analítica de material y artículos previos sobre los procesos de construcción paisajística en la provincia de Limón, Costa Rica (Contrastes de luz y sombra en el caribe costarricense. Reconstrucción del paisaje limonense desde los relatos de vida, en Revista de Ciencias Sociales, nro. 148, 2015).

* $\quad$ Escuela de Sociología de la Universidad de Costa Rica y Facultad Latinoamericana de Ciencias Sociales, Costa Rica. carballopablo@gmail.com 
colorful past remembered. In youth a comparison between the working world and new relationships is done. In adulthood / old age, which is where the three rapporteurs are, have given an interpretation from the changes that occurred, delving into their landscape emphasis. In the conclusion showing the conflicting and differential nuances - political and social - that every ethnic and cultural compound, based on the particular experience of the rapporteurs, pointing social complexity in relation to a multicultural landscape.

KEYWORDS: COSTA RICA * LANDSCAPE * CULTURE * MEMORY * HISTORY

\section{INTRODUCCIÓN}

Este documento es una continuación analítica en la profundización sobre los recuerdos, pensamientos y construcciones del paisaje desde el relato de tres personas que crecieron en la provincia de Limón, en la zona Caribe. El interés central es reconstruir el paisaje de la provincia limonense según consideraciones étnicas y socio-políticas, por lo que se recurre a referentes teóricos del paisaje, contexto histórico y al uso de los "relatos de vida" como estrategia metodológica.

Es importante rescatar que este documento se enmarca en los intereses de investigación del proyecto Centros Históricos del Turismo, hasta evolucionar en lo que es el proyecto actual denominado: La construcción social de los Paisajes: El Caribe y el Pacífico, de la Universidad de Costa Rica. El proyecto inició con un enfoque cuantitativo y evolucionó hacia el enfoque cualitativo, siendo una de las técnicas fundamentales que se usó y que seguirá siendo usada es la del relato de vida en perspectiva etno-sociológica (Bertaux, 2005).

Además, este ensayo tiene su base fundamental en el artículo "Contrastes de Luz y Sombra en el Caribe Costarricense", del cual se generaron las líneas de análisis fundamentales que aquí se profundizan; $y$ a su vez se complementan con otras valoraciones de carácter crítico y socio-histórico. Además, se brinda material directo de los relatos de vida, analizados previamente bajo la mirada teórica establecida en el proyecto de investigación indicado.

La problematización de la investigación de todo el proyecto, en la cual se inserta el presente artículo, plantea la siguiente interrogante:
¿Cuáles son las reconstrucciones sociales del paisaje caribeño desde los relatos de vida de personas que viven o han vivido en la zona? En ese sentido, el objetivo general es: analizar la reconstrucción paisajística del Caribe desde la dimensión étnica en tres relatores pero desde una mirada crítico hacia las visiones habituales de la región ${ }^{2}$.

El proyecto de investigación profundiza en varias dimensiones, transporte, recreación, mercado y etnicidad. En lo que respecta a este escrito, lo étnico es la variable que aglutina la reflexión y es a partir de la que se desprende la construcción de los relatos. La profundización étnica permite "orientar la justificación de las personas seleccionadas, así como un grupo de preguntas que componen la matriz de interrogación. Además, se muestra una dimensión culturalmente evidente, pero donde diferentes matices juegan fundamental importancia en la construcción de sentido sobre diferentes eventos, actos, $y$ por supuesto el paisaje" (Carballo, 2015). En otras palabras, el estudio macro es la re-construcción paisajística de la zona Caribe (provincia de Limón, Costa Rica), buscando evidenciar, desde el componente étnico, la variedad simbólica en los atributos al entorno, tanto personal, como socio-histórica.

\section{BREVE DESCRIPCIÓN METODOLÓGICA}

Como se señaló, el estudio versa sobre la reconstrucción de paisajes, su vivencia y la forma en que las personas la rehacen, de ahí

$2 \quad$ Una versión previa de este escrito se presentó como ponencia en el $V$ Congreso de Ciencias y Arte del Paisaje, Academia Mexicana del Paisaje (ACAMPA), Querétaro, México, setiembre de 2016. 
lo importante $y$ valioso de la técnica del Relato de vida (Bertaux, 2005), como elemento fundamental en la investigación. Además, al saber que la categoría que aglutinaba esta dimensión de la investigación general era lo étnico, se escogieron tres relatores que dieran evidencia del bagaje cultural y diverso de la composición social de la zona Caribe ${ }^{3}$. En la tabla 1 se muestran las personas consultadas, según una serie de elementos de composición de sus trayectorias de vida en relación con la región caribeña/ provincia limonense.

TABLA 1

INFORMANTES Y SUS CARACTERÍSTICAS SOCIO-CULTURALES

2013

\begin{tabular}{llll}
\hline ELEMENTOS & $\begin{array}{l}\text { RELATO A } \\
\text { JOYCELIN SAWYERS }\end{array}$ & $\begin{array}{l}\text { RELATO B } \\
\text { ARABELLA SALAVERRY }\end{array}$ & $\begin{array}{l}\text { RELATO C } \\
\text { OSCAR ZEN }\end{array}$ \\
\hline Consideración étnica & $\begin{array}{l}\text { Afrodescendiente } \\
\text {-autodenominada- }\end{array}$ & $\begin{array}{l}\text { Blanca } \\
\text {-autodenominada- }\end{array}$ & $\begin{array}{l}\text { China-Mandarín } \\
\text {-autodenominado- }\end{array}$ \\
$\begin{array}{l}\text { Espacio laboral } \\
\text { Ocupación }\end{array}$ & Docencia y Política & Arte & Comercio e inversión \\
Edad & Docente/política & Actriz/escritora & Ingeniero/Empresario \\
Infancia & En los setenta & En los sesenta & En los sesenta \\
Juventud-adultez & Limón & Limón & China \\
Vive actualmente & Limón & San José-Exterior país. & Limón \\
\hline
\end{tabular}

Fuente: Elaboración propia, basado en Carballo, 2015.

La pertinencia de ciertos abordajes metodológicos y de ciertas técnicas permiten tener una introducción en complejos sistemas de sentido, los cuales son fundamentales en el entendimiento de las vidas, así como de los proyectos y conflictos sociales que los habitantes de ciertas zonas o espacios sociales construyen, y aquí también está implícito la elaboración socio-histórica de los paisajes. En este línea:

El recurso de la entrevista es fundamental para lograr información pertinente, sin embargo, el interés es conseguir recabar los relatos de vida de las personas

3 Falta el tema/grupo indígena como fundamental en la composición étnica de la zona Caribe (y costarricense en general). Este grupo social está siendo abordado en la versión más reciente del presente proyecto. que se vaya a entrevistar. La justificación del empleo de los relatos de vida radica en que, mientras la entrevista es más cerrada en la mirada, el relato de vida se considera una herramienta que tiene por fundamento hacer un recorrido por el itinerario biográfico de las personas buscando entresacar dimensiones particulares, sean trabajo, lucha social, vida cotidiana, etc. (Carballo, 2015, p.84).

Como precisa uno de los principales exponentes, la técnica es “...un testimonio de la experiencia vivida, pero es un testimonio orientado por la intención de conocer del investigador que lo recoge" (Bertaux, 2005, p.51).

En este sentido, se expone un cuadro matriz (tabla 2) que precisa una serie de categorías que orientan la lectura sistemática de los tres relatos recuperados, $y$ donde a su vez dividen la biografía de las personas dentro de 3 marcos cronológicos de vida: niñez, juventud 
y adultez/vejez. Cada una de estas etapas está asociada con las variables que colindan con las connotaciones de paisaje y elementos importantes en el recorrido socio-histórico y político que Limón ha presentado. Como se verá, el factor a resaltar $y$ que se pone en contraste con mayor fuerza es el factor de la etnicidad, el cual es conceptualizado:

...cuando un grupo humano, por haber cristalizado como grupo étnico en el transcurso de un proceso histórico en el que sus miembros han participado de una experiencia colectiva básicamente común, posee una serie de elementos culturales específicos que actúan como marcadores de su diferencia objetiva respecto de otros grupos, es decir, como marcadores de su específica identidad (Moreno, 1985, p.13).

La etnicidad es el punto de convergencia de los análisis de reconstrucción paisajística y es el eje de articulación de los relatos de las personas desde sus biografías y desde sus valoraciones.

TABLA 2

MATRIZ ANALÍTICA DE LOS RELATOS DESDE EL EJE ÉTNICO 2013

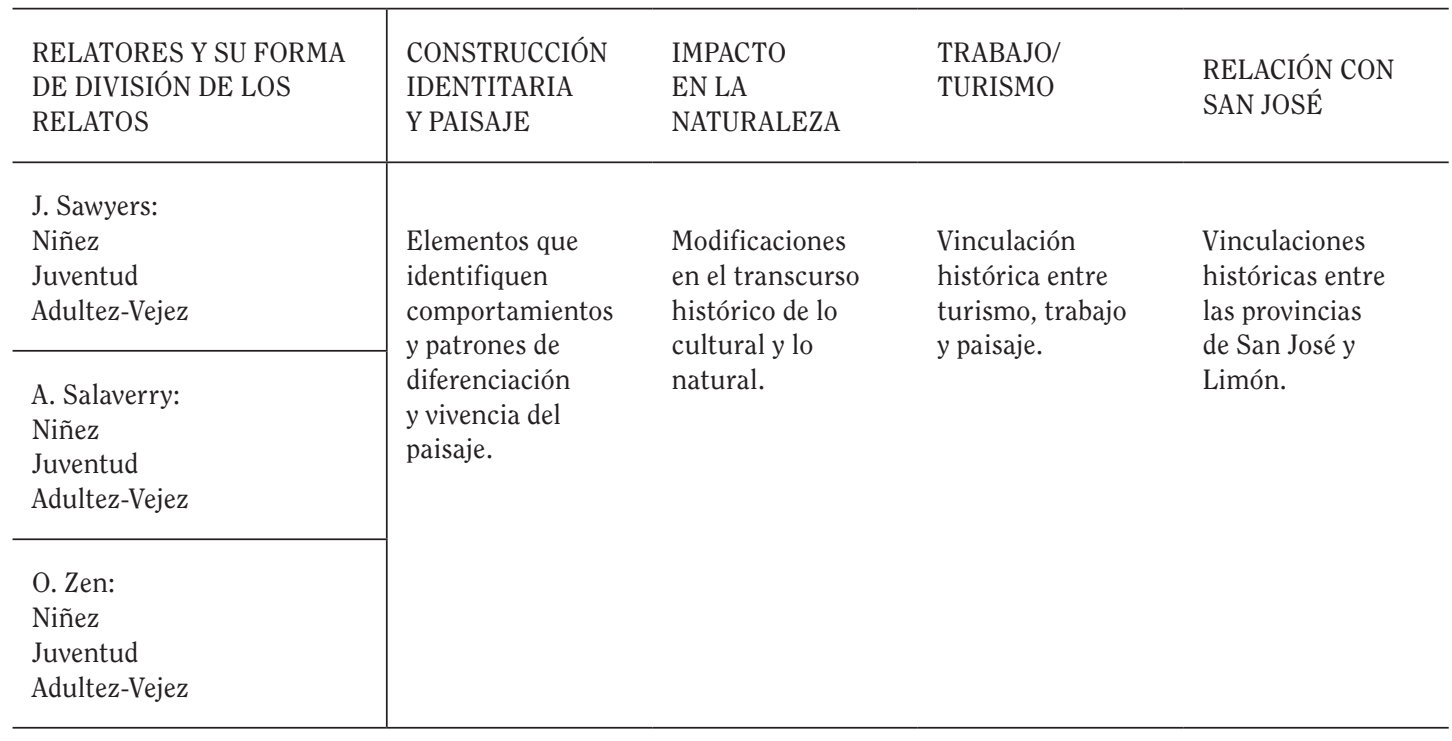

Fuente: Carballo, 2015.

Si bien, la división por etapas de vida permite distribuir momentos y coordinar el proceso de vivencia de las personas, es importante rescatar que puede existir entrecruzamiento de ideas $y$ valoraciones ambiguas. Esto se debe a que los relatores se encuentran en momentos de su vida adulta y de vejez, lo cual hace que en algunas oportunidades no se precisen ciertos recuerdos. Desde la técnica del relato de vida, esto no es un problema (pero sí un asunto de cuidado y perspicacia), ya que lo fundamental es la apreciación, junto con la labor de análisis y de reconstrucción de la persona investigadora.

Esta reflexión es importante, ya que permite encauzar las responsabilidades investigativas, así como valorar el uso y los aportes de cada una de las personas que en conjunto producen el material de investigación en relación 
con las vivencias individuales y colectivas que tiene esta parte del proyecto ${ }^{4}$.

\section{BREVES POSTULADOS TEÓRICOS SOBRE LA CONSTRUCCIÓN DE PAISAJE}

El abordaje de los paisajes se hace desde la mirada teórica de la construcción. Es decir, se basa en la idea de que se produce como sociedades, así como sujetos que participan y cohabitan en el entorno, condiciones y escenarios sociales o socio-biológicos. Esto presenta una posición materialista, donde resalta el empleo de la fuerza social, consciente o no, en la construcción de sus espacios vitales. En este sentido, la fuerza social es diferente $y$ dividida en pesos e insumos:

Las clases y grupos sociales que se estructuran en el marco del modo de producción son los que socialmente modelan el paisaje. Por una parte los grupos dominantes, darán forma a sus proyectos económicos, bajo modalidad de "planes de desarrollo", que serán sus propuestas de políticas para agenciar sus intereses económicos. En otras palabras, los nuevos ejes de acumulación se materializan mediante políticas de desarrollo y la actividad económica como tal (Cordero, 2012, p.4-5).

En esta misma línea se encuentra entonces que:

El paisaje es finalmente biografía, es decir, historia personal. (...) El trabajo, las acciones colectivas y la vida cotidiana, cómo lo dijimos anteriormente, van construyendo socialmente el paisaje. Se puede postular que no van construyendo a largo plazo.Como el paisaje se manifiesta en parte geográficamente, los

$4 \quad$ El proyecto global incorpora 12 relatos (con varias sesiones, dependiendo del relator o relatora), según cada uno de los ejes (mercado, transporte, recreación y etnicidad), por lo que el estudio de este artículo se refuerza realizando reflexiones cruzadas con los restantes 9 relatos; sin embargo, haciendo énfasis en los tres relatores clave en el marco étnico. cambios que acaecen en su apariencia a veces concurren a lo largo de períodos muy largos. Puede ocurrir, claro está que fenómenos ya sea de la naturaleza o del desarrollo social, provoquen cambios bruscos del paisaje (Cordero, 2012, p. 7).

En resumen, se está expresando una mirada analítica desde el reconocimiento de los grupos sociales como gestores clave en los escenarios que habitan, $y$ la teoría sobre paisajes es precisamente una indagatoria sobre esos procesos históricos de adaptación y ambivalencias sociales. En ese sentido, el objeto no es hacer un gran desarrollo teórico, sino resaltar varios puntos, como el anterior. Centrándose en una reflexión socio-históricamente en el caso de las zonas de estudio, donde el turismo ha sido una fuerza que ha tenido un significativo impacto en la modelación del paisaje limonense. Esto denota que:

El trabajo es un factor clave en la construcción y modificación de los espacios físicos, $y$ en este caso el turismo, como dinámica laboral y enlazada con los parámetros capitalistas han tendido a variar las miradas de las personas, generando razonamientos $y$ sentimientos que por medio del relato de vida buscamos captar (Carballo, 2015, p.89).

Se aprovecha esta ocasión para entresacar miradas críticas que cuestionen estereotipos o paisajes reificados de la zona caribeña, que se han elaborado a partir de la exterioridad $y$ que han monopolizado el territorio de lo imaginativo y lo social. Diferentes enfoques existen sobre la teoría del paisaje, desde Alain Roger (2007) y su versión asociada con la visión artística, hasta una postura de carácter materialista, como la que en este estudio/proyecto ha primado. Se escoge esta segunda mirada porque profundiza en el trabajo (como fuerza social e individual), lo que permite introducir en el tema de la participación y en la posibilidad de autovalorarse como constructor.

El complejo y dinámico marco teórico que existe sobre paisajes permite vislumbrar aristas de diferente relevancia. Sin embargo, 
en términos operativos para este documento, se propone una mirada compuesta por tres dimensiones: 1. la participación humana en la elaboración de sus escenarios, 2. la vivencia de esos escenarios, y 3. el reconocimiento de su participación en la creación y modelación de los escenarios que viven; esto también involucra reconocer visiones externas y contraponer o cuestionar críticamente dichas miradas, particularmente las que tienden al nacionalismohomogenizante.

\section{EL CARÁCTER SOCIO-HISTÓRICO DE LA PROVINCIA DE LIMÓN (EL CARIBE)}

Para comprender algunos de los elementos de los relatos de vida y apreciar su profundidad en un marco más amplio, es fundamental tener al menos 2 consideraciones socio-históricas de lo acontecido en la provincia de Limón y el Caribe en general. La comprensión étnica se despliega desde dicho marco contextual.

1) El Caribe fue y es un polo económico básico en el territorio. Tanto por las poblaciones indígenas que la habitaron $y$ habitan como por el impacto $y$ función en la consolidación del EstadoNación (Boza, 2015). Su característica de puerto (Atlántico), fue fundamental en el desarrollo del modelo basado en la bipolaridad de los productos históricos de exportación del país: café y banano. El café como producto de la élite local, ubicada en el centro del territorio, y el banano ubicado en las costas, teniendo gran auge en la provincia de Limón. Es fundamental señalar que la administración (producción y comercialización) del banano fue realizado por empresas internacionales (particularmente la United Fruit Company ${ }^{5}$ ). Lo cual estuvo

5 Dos de las principales figuras de este proceso fueron el inversionista Minor Cooper Keith (Creador de la United Fruit Company en 1899) y el ex ministro y después ex presidente de Costa Rica, Bernardo Soto Alfaro. relacionado con el auge de la infraestructura vial para el transporte ferroviario $y$ portuario. La industria bananera fue una de las razones fundamentales para la concreción de un crisol étnico en la zona, debido a que se involucró personas de diferentes lugares (locales/nacionales y extranjeros/internacionales). De ahí que la misma creación del sistema de transporte, en particular el ferrocarril al Atlántico, fue una producción paisajística donde estuvo presente de lleno la pluralidad étnica. Y además la política externa de Costa Rica de corte civilizatorio y modernista también permitió por otro lado que "inversiones y usureros desarrollaran y estafaran" al Estado, y a su vez crearan un monopolio bananero en la región (González Víquez citado en Quesada, 2001).

2) La composición multiétnica del Caribe es uno de los rasgos característicos de la zona. Esto se debió al impacto mencionado en el anterior punto respecto a la construcción del ferrocarril.

En Costa Rica, y con el propósito de construir el ferrocarril que conectara el Valle Central con los territorios en su franja caribeña, se recurrió a las inmigraciones, inclusive de otros continentes. Sin embargo, un contingente laboral se destacaría entre todos ellos: la población afrocaribeña; $y$ entre esta población, la población de nacionalidad jamaiquina (Senior, 2011, p.xIII).

Este elemento es fundamental, ya que la captación de mano de obra migrante abasteció a la zona de una pluralidad étnica fuerte, desde los afrocaribeños, hasta la población china que también fue importante. A su vez, dicha 
pluralidad fue contrarrestada por una visión nacionalista y blanca desde el Valle Central, donde el gobierno

...estableció medidas específicas para esta región, fundadas en la conceptualización de la "higiene pública". Estas ideas formaban parte de la ideología racial imperante en la sociedad, basada en el mito de la Costa Rica blanca e igualitaria, muy a pesar de su heterogénea población nacional constituida desde la época colonial (Senior, 2011, p.13).

Estos dos elementos (entre otros), fuertemente asociados, marcan una línea socio-histórica para analizar y contextualizar con mayor profundidad los relatos, así como ahondar en reflexiones más complejas de las dinámicas étnicas y socioterritoriales que involucran la construcción de paisajes en la zona, y a su vez cuestionar miradas paisajísticas prehechas desde la exterioridad que, recubiertas de estereotipos nacionalistas, han marcado y marcan la mirada global del país hacia la región y sus habitantes.

\section{ANÁLISIS DE LOS RELATOS DE VIDA SOBRE PAISAJES}

La intención es señalar una línea de discusión y análisis usando como elementos fundamentales los extractos de las y los relatores. La forma de hilo conductor se divide en los contextos de niñez, juventud y adultez/vejez. Así:

El objeto será explorar las variables de la matriz base, y poder descomponerla para rescatar los aportes específicos según la forma expresiva que las personas consultadas señalaron. El material teórico funciona para realizar la lectura desde la mirada de impacto de las relaciones sociales en la variación y modificación en la construcción del entorno paisajístico (Carballo, 2015).

\section{1) LA NIÑEZ Y LA CONSTRUCCIÓN IDENTITARIA}

La etapa de la niñez es un momento neurálgico en la elaboración de las identidades $y$ de los comandos sociales que serán pilares en las formas de comportamiento. Dicha etapa es cuestionada posteriormente durante los procesos de socialización y surgen conflictividades, pero es en la niñez donde el marco de referencia base es construido y a su vez, se moldean las formas de apreciación social iniciales de las cosas y miradas asociadas. Es importante aclarar que:

Cuando se habla de construcción de identidad, no estamos haciendo una reflexión en las estructuras psicológicas, sino estamos hablando desde los elementos que en la niñez son recuperados en los relatos, y que marcan la posibilidad de valorar, tanto lo relevante para la persona que genera el relato, así como elementos que ayuden a recrear la vivencia del paisaje con sus características retomadas (Carballo, 2015, p.90).

Aunado a esto, las formas culturales impactan en las instancias iniciales y se vuelven filtros condicionantes en las miradas paisajísticas. Culturalmente, la apropiación y la vivencia del paisaje en la etapa temprana naturaliza y condiciona un paisaje ideal en muchos casos, lo que se convierte en alguna medida de un "deber ser", al mismo tiempo, esto permite vislumbrar a nivel del relato los énfasis en el antes y el después, basados en los códigos morales y estéticos que, aunque cambian, están presentes en buena medida en las miradas de las personas desde sus primeros valores asociados a cómo "debe ser" ese paisaje.

En la tabla 3, se aprecian fragmentos que componen la importancia de los recuerdos de niñez según muestra valoraciones o miradas iniciales en relación a cómo fue y debe ser ese paisaje, así como con los detalles estéticos. 
TABLA 3

FRAGMENTOS DE LOS RELATOS PARA EL ANÁLISIS DE LA NIÑEZ

2013

\section{RELATORES CONSTRUCCIÓN DE IDENTIDAD CULTURAL Y PAISAJE}

Rasgo paisajístico-cultural: "Ninguna provincia ganaba el parque de Limón. ¡Ninguna! Vea no había nada más bonito en Limón que el parque, una cosa que no existía, ese montón de tierreros, ese montón de gente vaga, ese montón de gente bañándose en... ¿Cómo se llama eso donde está el agua del parque? J. Sawyers iEn la fuente, eso era sagrado! Eso era sagrado, naaadie se bañaba en esa fuente, después acuérdese yo no sé si eran los martes o los miércoles cuando la banda bajaba, eso ya no se hace, jay, que lindo vea!, venía la banda y todo el mundo con su cosa iban al quiosco del parque y ahí daban. ¿Cómo se llama lo que dan las bandas? Una retreta, ya eso no se da, entonces el paisaje cambio, esa belleza cambió”.

Rasgo paisajístico-cultural: "No, el parque estaría aquí, aquí estaba el club Miramar y el parque era como una lengüetita, ahora hicieron una cosas espantosa (risas) y bueno todo ese mundo glamoroso además del club Miramar estaba el Banana Boat que estaba en la zona bananera y había ahí unos bailes y unas fiestas impresionantes, toda la época de, del carnaval o del 12 de octubre por ahí, me trajeron fotos de una tía que se acaba de morir y hay algunas fotos de los 50 creo y de los bailes de disfraces que hacían porque siempre el baile tradicional del 12 de octubre era un baile de disfraces, entonces ahí se siente la elegancia, los que no llegaban disfrazados llegaban de traje con corbata, por ahí tengo que no la encontré una foto de los profesores del colegio también todos de saco y corbata elegantísimos siempre llegaban a dar clases así, a mí me tocó ver a los profesores de secundaria dar clases así y en la época de mi abuelo que por ahí había fotos también no solo era saco y corbata sino que chaleco y sombrero".

Rasgo paisajistico-cultural: "En las playas no ha cambiado mucho pero hay un gran cambio este Parque Vargas, eso cambió por dos partes, uno por terremoto, otro parte es por descuido. (...) Un ejemplo antes de terremoto eso parque llena de animales, todo tipos perezosos, (...) eh, mari, mariposas, los pajaritos, todo tipos, yo he visto una lechuza blanca que parada como 80 centímetros de altura fue aquí increíble,

O. Zen después de terremoto un año después comenzó cayendo árboles entonces yo fui a municipalidad entonces tuvo yo fui a municipalidad y dice que el primero que cae ten cuidado se va a caer todo, tienen que hacer un estudio como a cantante árboles porque sin eso árboles sin animales, ellos me vieron como un loco, que tiene que ver con usted, que importa uno, eso pienso yo por eso se llama descuido es punto, porque ellos nadie iba a preguntar porque están cayendo árboles y cuando esos árboles unos cuatro, cinco, seis de grandes todo se cayó ahí se todos de animales".

Fuente: Carballo, 2015.

\section{ANÁLISIS DE LA ETAPA DE LA NIÑEZ: PAISAJE E IDENTIDAD}

De manera puntual, se puede señalar que en esta etapa:

Se presenta un Limón no negro, sino diverso, multicolor. Y en la diversidad, si bien la negritud cumple un rol fuerte en términos culturales, las desigualdades también son parte del complejo sistema social, pero que pese existir, los relatos también señalan matices respecto a la forma de operar. Los narradores vivieron en un Limón que recuerdan cargado culturalmente con diferencias, y con espacios de belleza natural. Ambos presentes en una reflexión desde la elegancia, y que hoy ha "perdido" su "brillo", y su estilo (Carballo, 2015, p.92).

Esta perspectiva es clave para comprender la mirada interna sobre la provincia o región, que se enfrenta a una mirada externa valle-centralista de Costa Rica (meseteña), donde Limón (el Caribe en general) se le ha asociado histórica y discursivamente como un 
Limón negro, se le ha aplicado un código social racista y se le ha negado una visibilización más compleja de su bagaje multicultural. Esta versión de reconstrucción del paisaje, desde la mirada sociológica, hace una crítica a esta visión parcializada y políticamente desigual en la presencia social de la diversidad.

La visión desde la niñez deja ver una mirada paisajística con criterios altamente estéticos, entremezclados con elementos de belleza (entre ellos, ropajes y sobre todo el parque Vargas). Esto conduce al camino crítico de cuestionar la igualdad histórica costarricense, que se enfrenta con este comando de diversidad $y$ alerta de un choque conflictivo de la identidad nacional basado en la igualdad nacionalista versus una diversidad socioétnica que afirma un limón histórico más amplio en colores, que el discurso racial del "blanco y negro" políticomediático (Carballo, 2015).

\section{2) LA JUVENTUD: TRABAJO Y VISIONES DE MUNDO}

La etapa de la juventud presenta un inmersión en un mundo social más extenso, donde el trabajo y la búsqueda de este se vuelve fundamental en los procesos de interacción de las personas. Así:
En la etapa de la juventud, dos de las acciones más importantes que se pueden recordar en relación con el interés del artículo es el inicio de la vinculación con la dimensión laboral, así como la movilización. Y donde San José se convierte en un importante espacio de captación laboral de mucha de la población de las provincias del país (Carballo, 2015, p. 92).

Lo anterior marca una nueva dimensión al valorar el propio paisaje desde un alejamiento o desde un contraste con lo que existe en otros espacios y lugares. San José, como capital estatal, capta buena parte de los empleos y expectativas de trabajo, lo cual a su vez crea nuevas miradas de lo caribeño o limonense. Además, esta comparación con la capital permite repensar las expectativas y el bienestar o malestar respecto a la provincia.

La tabla 4 engloba un cúmulo de fragmentos que muestran esta vinculación con el entorno laboral más allá de los confines del espacio caribeño. En dicha tabla se subdivide en dos tipos de fragmentos: turismo y trabajo; $y$ relaciones con San José (capital de Costa Rica), para valorar el tipo de contenido simbólico respecto a dichas dimensiones. 


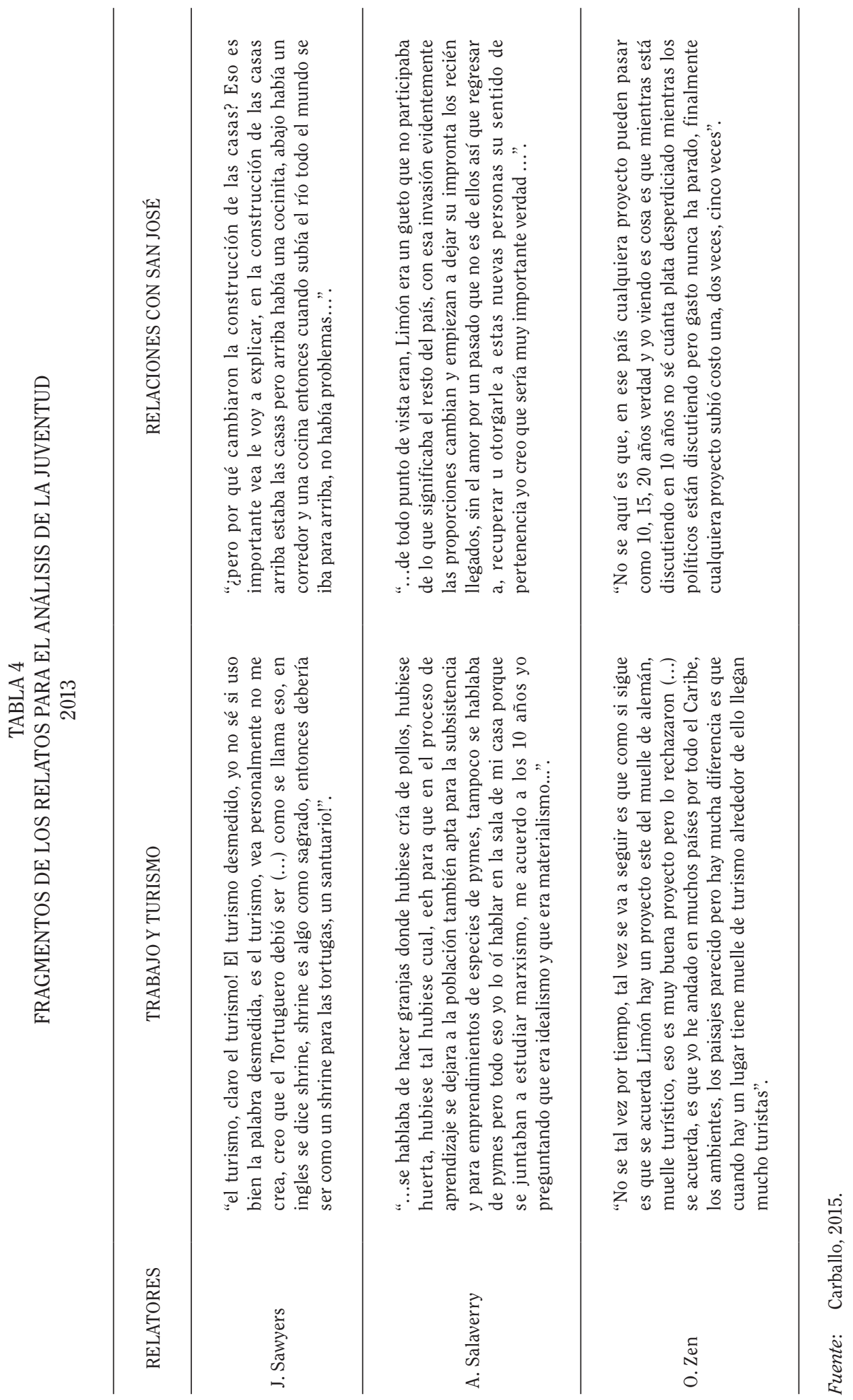

(c) (i) (8) $\odot$ Rev. Ciencias Sociales Universidad de Costa Rica, 158: 13-28 / 2017 (IV). (ISSN: 0482-5276) 
ANÁLISIS DE LA ETAPA DE LA JUVENTUD: EL TRABAJO Y LA "MIRADA AL EXTERIOR"

De esta manera, se resumen los tres tipos de paisaje:

...se evidencian tres estados de la vinculación, o lo que podríamos llamar tres "paisajes deseados". Un paisaje de no explotación de lo natural: un paisaje "virgen" —que sería el de la primera relatora-. Un paisaje de "equilibrio" y necesidad — de la segunda relatora-Y el último sería un paisaje "extensivo", es decir, de uso globalizado - en el caso del último relator- (Carballo, 2015, p. 94)"

Cada "paisaje deseado" estaría mostrando un posicionamiento práctico, donde esta tipología presenta que las formas de construcción social en la región y sus elaboraciones paisajísticas han estado marcadas por un corpus de ideas/valores según marcas étnicas (y sus marcos históricos).

Lo "virgen" está asociado a una idea de aquello que se considera natural y en un sentido puro; el "equilibrio" por su lado se asocia a la idea de usar, pero cuidando el medio ambiente que se podría asimilar con lo paisajístico; y por último lo "extensivo" se relaciona con el aprovechamiento global del recurso natural y paisajístico del entorno (Carballo, 2015). Ante lo anterior, lo importante es que se expresan intensiones más complejas de cómo se interactúa con lo ambiental, lo que acerca a la idea de participación, en especial en los tipos "equilibrio" $y$ "extensivo", pero que tienen condicionantes $y$ consecuencias socio-ambientales.

\section{3) LA ADULTEZ/VEJEZ: IDENTIDAD, LO EXTERIOR Y} LO NATURAL

En un contexto de vidas vividas, la adultez se presenta como un espacio donde aparecen dinámicas de consolidación y en el caso de la vejez, miradas que rondan la finalización de procesos (aunque no exclusivamente), y no necesariamente en todos los casos. Sin embargo, el factor de rutinas $y$ vinculaciones, valoradas positiva o negativamente, generan valorar el peso de lo externo en dichas consolidaciones de vida.

Así, dos temas que relucen en el escenario actual de las personas son el factor de la relación con San José que viene desde la juventud y el espacio turístico, pero también la reelaboración de los valores que se han reconstruido hasta la fecha (Carballo, 2015, p.94).

Es decir, esos mundos de vida construidos $y$ en los que hoy viven, hacen repensar el Caribe limonense desde sus cambios y sus formas de vida. La reflexión entre la niñez $y$ la juventud de las personas y sus respectivas confrontaciones o variaciones genera revaloraciones sobre "lo perdido" y "lo ganado", entre otras apreciaciones, así también expresan miradas menos estáticas y más móviles, al partir de que se evidencia el cambio o los cambios sociales.

La tabla 5 expresa dichos cambios, divididos según un impacto josefino en la naturaleza y según lo que se podría llamar un cambio en lo identitario. Los fragmentos expresan sobre todo la idea de cambio, sea en términos promisorios o de problemas. 


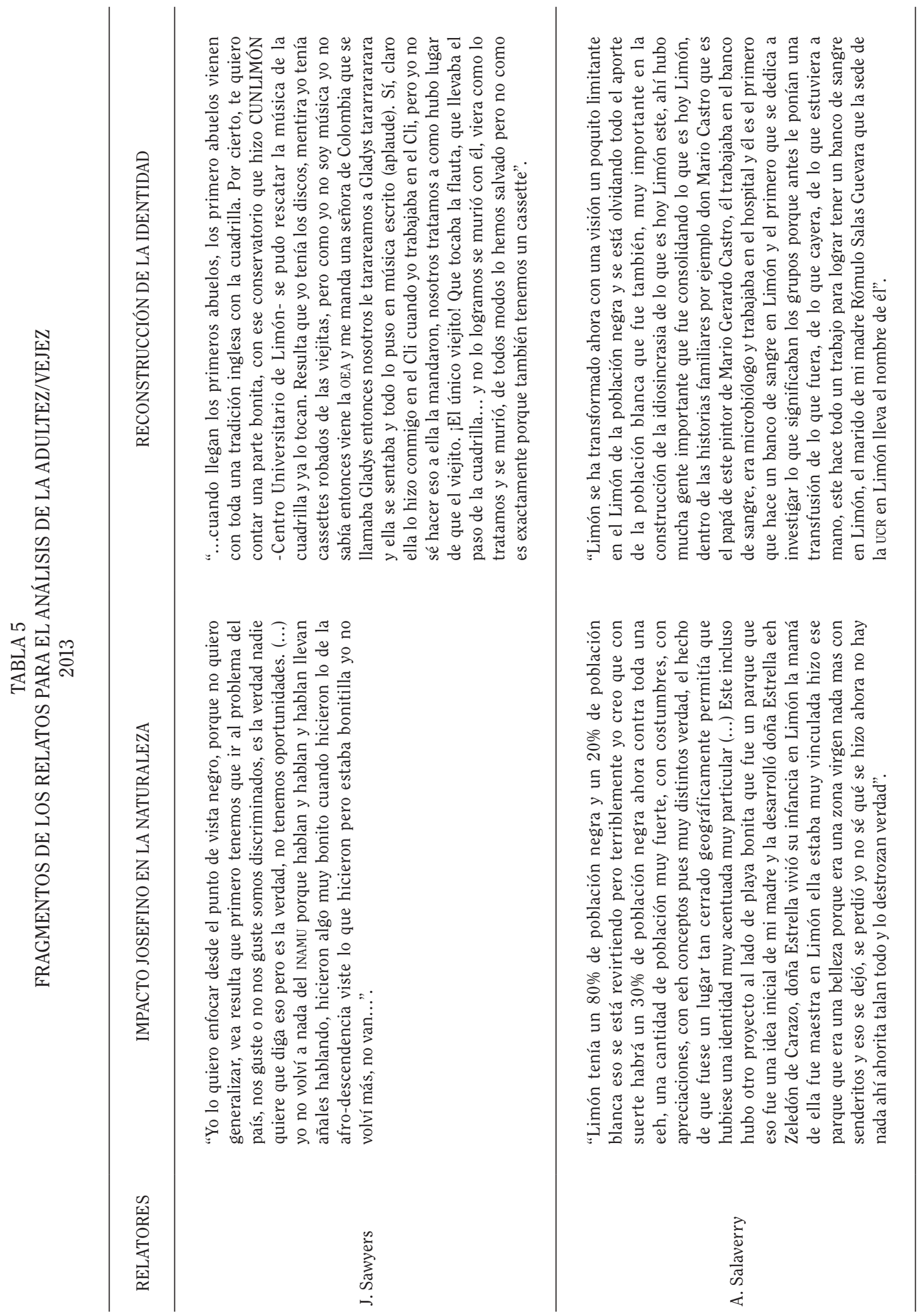

(c) (i) (8) $\odot$ Rev. Ciencias Sociales Universidad de Costa Rica, 158: 13-28 / 2017 (IV). (ISSN: 0482-5276) 


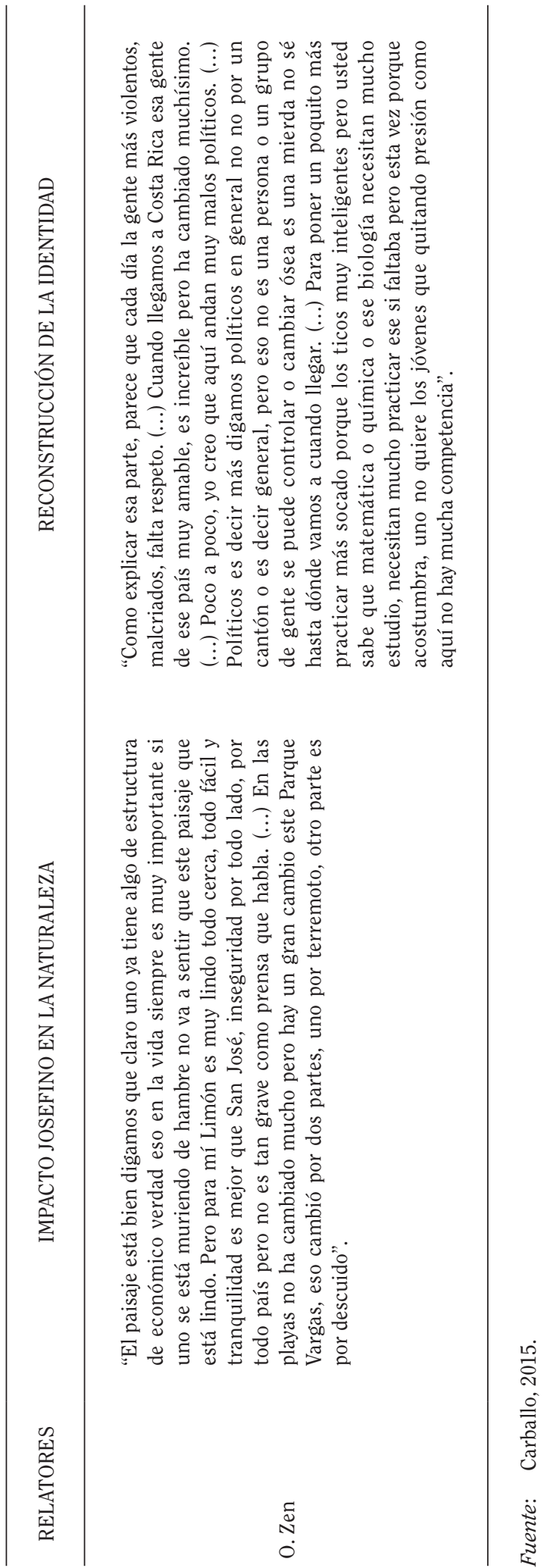


ANÁLISIS DE LA ETAPA DE LA ADULTEZ/VEJEZ: TURISMO Y RECONSTRUCCIÓN DE VALORES

Una reflexión importante radica en la idea de degeneración o pesadumbre de los elementos fundamentales que albergaba Limón, es decir, una destrucción del Limón "viejo", frente al "nuevo" Limón decolorado. La reconstrucción de la identidad se ve desde una lectura de deterioro, que se expresa en lo paisajístico también. Si bien, existen otras formas de analizar el fenómeno desde lo identitario, si se mira el fenómeno desde lo paisajístico, se ve que la idea que se reitera es la de descomposición: "Es decir, la idea de descomposición o de un "progreso" con consecuencias degradantes del ambiente, es al mismo tiempo un indicador visual de la degradación social y de la descomposición de los "valores" étnicos propios de las personas limonenses" (Carballo, 2015, p.97).

Se logra rescatar una serie de ideas $y$ contrastes donde los choques de las actividades económicas que redundan en alteraciones en el o los pasajes caribeños. Desde la lectura de intereses biográficos y étnicos se confrontan visiones diversas de lo que ha ocurrido en el contexto y sus derivados sociales. Esta última etapa de vida, incluye a las miradas paisajísticas ideas o razones del porque de dicha descomposición, lo cual engrosa la comprensión social de los paisajes desde las significaciones de las biografías y sus respectivos contextos étnicos e históricos.

\section{CONCLUSIONES CRÍTICAS DESDE UNA PERSPECTIVA SOCIO-HISTÓRICA}

Las etapas de niñez, juventud y adultez/ vejez permiten abordar las valoraciones de las personas, reconstruidas desde la técnica de los "relatos de vida". Desde esa división se pretendió elaborar miradas analíticas sobre el paisaje como elementos socio-vivencial y productivos, con reservas y limitaciones. En dichas miradas, el entorno paisajístico se presenta en dinámicas de modificación y en relación con personas, procesos sociales y entorno natural. A su vez, develan juegos político-ideológicos donde la desigualdad tiene presencia en el recorrido histórico de la construcción social de la región limonense y caribeña en general.
Una de las principales formas analíticas que hay que rescatar de la reconstrucción paisajística es el valor de lo plural y sobre todo, lo multicolor. Este elemento muestra una lógica identitaria que señala diversidad. Como se adelantó, esto marca una importante crítica al valor de igualdad (Sojo, 2010) con la que se compone discursivamente el espectro ideológico nacionalista de Costa Rica. La valoración desde la pluralidad cultural, y por ende de la diferencia en matices de formas y comportamientos, releva la desigualdad que se ha camuflado en buena medida desde la idílica sociedad igualitaria costarricense; donde el Limón exclusivamente negro, se ha compuesto como un extremo distorsionador de la igualdad mítica pura de "lo costarricense". Este referente analítico es importante considerarlo, ya que enlaza el factor socio-histórico y político de una vida contrastante entre el centro del país idealizado "blanco" y todo lo externo al país en términos simbólicos, como las zonas costeras "no blancas" y con migrantes.

Sucede así que se ha presentado una mirada paisajística externa (capitalina) basada en los estereotipos históricos respecto a un Limón exclusivamente negro, que por un lado es solamente negro - una racialización homogénea-; y por otro lado, niega la diversidad étnica de la región - una racialización excluyente. La racialización homogénea es identificar como iguales a todos en la provincia, iguales entre ellos; pero diferente con iguales vallecentralinos (los "blancos" iguales) (Sojo, 2010). Asimismo, la racialización excluyente, que solo admite una "raza" $y$ los demás son opacados por ser etiquetados como migrantes, o por un nulo conocimiento sobre la diversidad que redunda en exclusión social-nacional.

En términos más específicos, se puede individualizar las miradas paisajísticas y notar como el uso y concepción del entorno varía, y se ajusta a las esquematizaciones de cada relator o relatora según su imaginario histórico-étnico. Para eso se construyó una puntual tipología (con el fin de poder reconstruir la mirada desde las narraciones $y$ dar sentido a lo que ellos perciben y viven). Así, se organizó y diferenció los 
marcos socio-históricos y subjetivos de las personas consultadas, que se recuerdan a partir de los hallazgos teórico epistemológicos del proyecto de investigación. Se tiene así que:

La reconstrucción del paisaje se hizo apelando a una vida ya desarrollada de las y él relator, ya que los tres superaban la edad de los 60 años. En este sentido cada uno hizo una reconstrucción de cómo debía funcionar la relación entre turismo y naturaleza, esto con la idea de resguardar la belleza rememorada de lo natural de su infancia. De ahí la idea de utilizar el término de "paisaje deseado" que eran: A. paisaje "virgen", B. paisaje de "equilibrio", y C. paisaje "extensivo". Con este criterio se resume la concepción de que cada relato entraña una forma distinta del "deber ser" de la relación laboral. Sin embargo, ese "deber ser" de cada relato busca que lo natural se recupere o mantenga su color, tanto natural como podríamos presuponer, la pluralidad étnico-cultural. Además, lo económico-político es un elemento que recorre los relatos de manera sombrea$\mathrm{da}$, es decir, como un elemento indiferenciado en la mayoría de los casos, donde forman parte de un contexto político poco profundizado, por razones de los mismos relatos, como por la dinámica de la técnica de relato aplicada. Pero que sí es mencionado en función de su conexión con el tema del desarrollo como discurso hegemónico (Carballo, 2015, p.97-98).

De lo anterior es importante recordar la fuerte idea de deterioro general de la provincia, y que impacta en la valoración paisajística de manera importante. Dicho elemento es recurrente en dos de los relatos, que coinciden con las mujeres que desarrollaron su niñez en la región. El tercer relato, que no expresa tan fuertemente esta idea no vivió su infancia en el país, sino que migró en su juventud al Caribe costarricense. De ahí que el peso biográfico esté orientado tanto a otros intereses, como a otras valoraciones respecto a lo que el paisaje significa y aporta en el entramado de las vivencias.

Esto no quiere decir que no haya apreciación de belleza, utilidad, entre otros, sino que la forma de valorarla está en otros cometidos o escala de valores. El elemento simbólico que agrupa lo que se ha caracterizado como un deterioro, llamado en esta investigación como una decoloración debido a que:

Esta decoloración la podemos interpretar como una de las lecturas que hacen las y él entrevistado de la relación entre turismo, vínculos laborales y con San José. Donde una de las consecuencias más reconocibles es el deterioro biótico, es decir, el deterioro del paisaje natural. Pero que todavía se concentra en elementos puntuales como playas o sitios categorizados como turísticos (Carballo, 2015, p.97).

La decoloración es una forma de analizar la pérdida que los relatores indican de la diversidad social según valores específicos; $y$ cómo el factor de lo externo, concentrado en la actividad turística, ha tenido un fuerte impacto en dicha pérdida de color. No se puede pasar por alto tampoco una reflexión del contexto socio-económico global, que dejan entrever que:

...las formas que el modelo de producción presiona sobre las formas relacionales en el trabajo y el uso extensivo de los recursos naturales, ha modificado las formas de mirar no sólo lo natural, sino también las mismas relaciones cotidianas de las personas, como los relatos muestran (Carballo, 2015, p.98).

Esto alerta sobre la importancia de valorar los relatos, no solo en su sentido subjetivo y narrativo desde las biografías, sino de la vivencia de procesos estructurales amplios y dinámicas, donde aparecen elementos puntuales de los sistemas socioeconómicos en vigencia. 
BIBLIOGRAFÍA

Bertaux, D. (2005). Los relatos de vida. Perspectiva Etnosociológica. Barcelona: Bellaterra.

Boza, A. (2014). La frontera indígena de la gran Talamanca: 1840-1930. San José, Costa Rica: Editorial de la Universidad de Costa Rica.

Carballo, P. (2015). Contrastes de Luz y Sombra en el Caribe Costarricense. Reconstrucción del paisaje limonense desde los relatos de vida. Revista de Ciencias Sociales, (148), 93-99.

Cordero, A. (2012). Paisajes y relatos de vida. Proyecto Centros Históricos del Turismo: Apuntes para el marco teóricometodológico. Documento inédito. Universidad de Costa Rica.

Moreno, I. (1985). Etnicidad, conciencia de etnicidad y movimientos nacionalistas: aproximación al caso andaluz. Revista de Estudios Andaluces (5), 13-38. Recuperado el 09 de Septiembre de 2013 de http://institucional.us.es/revistas/ andaluces/5/art_1.pdf

Quesada, J.R. (2001). Historia de la historiografía costarricense. 1821-1940. $1^{\text {a }}$ ed. San José, Costa Rica: Universidad de Costa Rica.

Roger, A. (2007). Breve Tratado del Paisaje. Madrid: Biblioteca Nueva.

Senior, D. 2011. Ciudadanía afrocostarricense. El gran escenario comprendido entre 1927 y 1963. $1^{a}$ ed. San José, Costa Rica: Universidad Estatal a Distancia y Universidad de Costa Rica.

Sojo, C. (2010). Igualiticos. La construcción social de la desigualdad en Costa Rica. $1^{\mathrm{a}}$ ed. San José, Costa Rica: flacso.

Fecha de ingreso: 31/10/2016 Fecha de aprobación: 18/05/2017 